\title{
Erratum to: Advantages of new technologies in oral mucosal surgery: an intraoperative comparison among Nd:YAG laser, quantic molecular resonance scalpel, and cold blade
}

\author{
Ilaria Giovannacci ${ }^{1} \cdot$ Marco Meleti $^{1} \cdot$ Elisabetta Merigo $^{1} \cdot$ Giovanni Mergoni $^{1}$. \\ Carlo Fornaini ${ }^{1} \cdot$ Maddalena Manfredi $^{1} \cdot$ Mauro Bonanini $^{1} \cdot$ Paolo Vescovi $^{1}$
}

Published online: 20 August 2015

(C) Springer-Verlag London 2015

Erratum to: Lasers Med Sci

DOI 10.1007/s10103-015-1769-7

The original version of this article, unfortunately, contained error in the author group.

Given names and family names were interchanged resulting to incorrect citation of the paper. The correct presentation of the authors' names is given above.

The online version of the original article can be found at http://dx.doi.org/ 10.1007/s10103-015-1769-7.

Marco Meleti

marco.meleti@unipr.it

Department of Biomedical, Biotechnological and Translational Sciences, Center of Oral Laser Surgery and Oral Medicine, Dental School, University of Parma, Via Gramsci, 14-43125 Parma, Italy 